\title{
AC Resistance of Air Core Coils Using Magnetoplated Wires
}

T. Mizuno, A. Kamiya, K. Iida, Y. Shimura, D. Yamamoto, T. Fujimatsu, C. Ikeda*, and H. Sasadaira* Shinshu University, 4-17-1 Wakasato, Nagano, Nagano, 380-8553, Japan

"Totoku Electric Co., Ltd, 300 Oya, Ueda, Nagano, 386-0192, Japan

\begin{abstract}
Air core coils are widely used in induction cooking appliances and transformers. To improve their efficiency, two characteristics are required: high combination and low loss. We propose that a litz wire using magnetoplated wires (MPWs) be used as the conductor material of a coil. Theoretical expressions for the ac resistances due to the skin and the proximity effects of air core coils using copper wires (COWs) and MPWs are derived. The calculation errors of the ac resistances of air core transformers using COWs and MPWs in the frequency range from $100 \mathrm{kHz}$ to $1 \mathrm{MHz}$ are $10 \%$ and $22 \%$, respectively. The resistances of air core coils using COWs and MPWs at a frequency of $1 \mathrm{MHz}$ are $43.2 \mathrm{~m} \Omega$ and 29.2 $\mathrm{m} \Omega$, respectively, $34 \%$ less than of conventional air core coils.
\end{abstract}

Key words: air core coil, ac resistance, magnetoplated wire, litz wire, theoretical expression, skin effect, proximity effect

\section{磁性めっき線を用いた空心コイルの交流抵抗}

水野勉，神谷 旭，飯田 和剛，志村 祐介，山本 大輔，藤松 拓也，池田千里“，笹平秀昭*

信州大学工学部, 長野県長野市若里 4-17-1 (380-8553)

“東京特殊電線，長野県上田市大屋 300（386-0192）

\section{1.まえがき}

空心コイルはIH調理器や非接触給電トランスに用いられ ている ${ }^{1) ~ 3)}$. 電磁界共振結合を用いた非接触給電では数 $\mathrm{MHz}$ での駆動が有望視されている ${ }^{3)}$.これらの応用分野で は,効率を向上させるためにコイルの結合度の向上と損失 の低減が課題となっている ${ }^{4) 5}$. 損失低減のためには,コイ ルの交流抵抗を低減させる必要があり，リッツ線が使用さ れている.リッツ線は，表皮効果に起因する抵抗低減効果を 有している.さらなる交流抵抗の低減のためには近接効果 に起因する抵抗の抑制が必要である .

筆者らは空心コイルの交流抵抗低減のために, コイルに 磁性めっき線(以下，MPW)を用いたリッツ線(以下,LMW) を用いることを提案している ${ }^{6) 8}$ ). MPW は, 銅線(以下， $\mathrm{COW})$ の外周に磁性薄膜をめっきした構造を有しており， (a)インダクタンスの増加，(b)交流抵抗増加の抑制，の特徵 がある.上述の(a)は磁性薄膜の透磁率が大きいことに起因 している．また，(b)は銅に比べて透磁率と抵抗率の両者が 大きな磁性薄膜内を交流磁界が通過するために,COWと比 較して導線内で生ずる渦電流損を低減できることに起因し ている。

本論文では,リッツ線を用いた空心コイルの交流抵抗を 求めるための理論式を明らかにしている.この理論計算で は,リッツ線の素線 1 本ごとを考慮しており，抵抗 (直流抵 抗，表皮効果に起因する抵抗，近接効果に起因する抵抗)の 各成分ごとに求めることができる.さらに, LMW と COW を用いたリッツ線 (以下,LCW) の空心コイルの抵抗を実 測してLMWの有用性について検討する.本論文では, 以下
の事項について述べる .

1) 空心コイルの交流抵抗の理論式

2) LMW の有用性

\section{2. 空心コイルの構造}

Fig. 1 に COW と MPW の構造を示した . $\mathrm{COW}$ は銅 $(\mathrm{Cu})$ 線 $\varnothing 50 \mu \mathrm{m}$ の外周に厚さ $4 \mu \mathrm{m}$ の絶縁層か設けられている. $\mathrm{MPW}$ は, 銅 $(\mathrm{Cu})$ 線 $50 \mu \mathrm{m}$ の外周に $\mathrm{Fe}$ 薄膜と $\mathrm{Ni}$ 薄膜がめつ きされている ${ }^{819)}$. Fe 薄膜と Ni薄膜の厚さは,乥れ光れ $0.6 \mu \mathrm{m}$ と $0.05 \mu \mathrm{m}$ である. Ni 薄膜は，はんだ付けを容易にするた めに設けてある .

Fig. 2はリッツ線の撚り方である.まずFig. 1に示した導 線をFig. 2 (a)のように，素線 60 本撚り，孫撚りを作成し

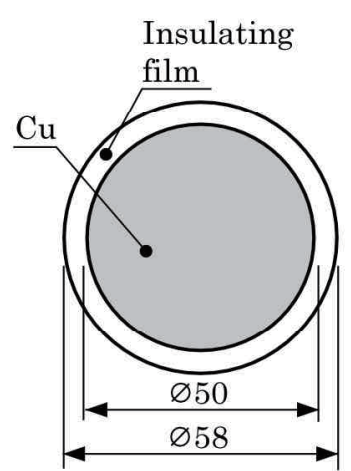

(a) $\mathrm{COW}$

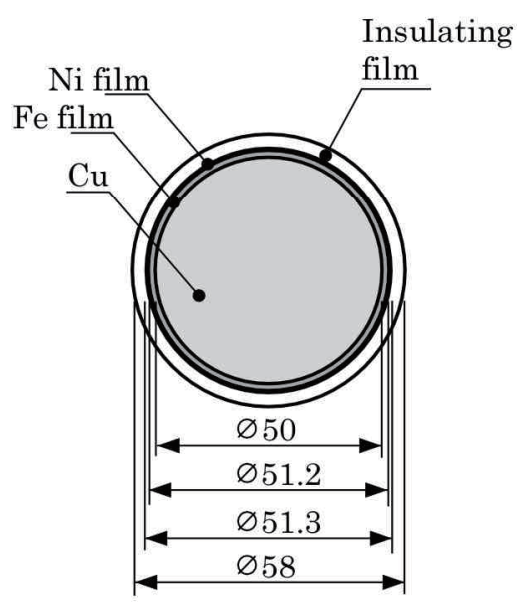

(b) MPW
Fig. 1 Structures of a COW and an MPW (unit: $\mu \mathrm{m}$ ). 


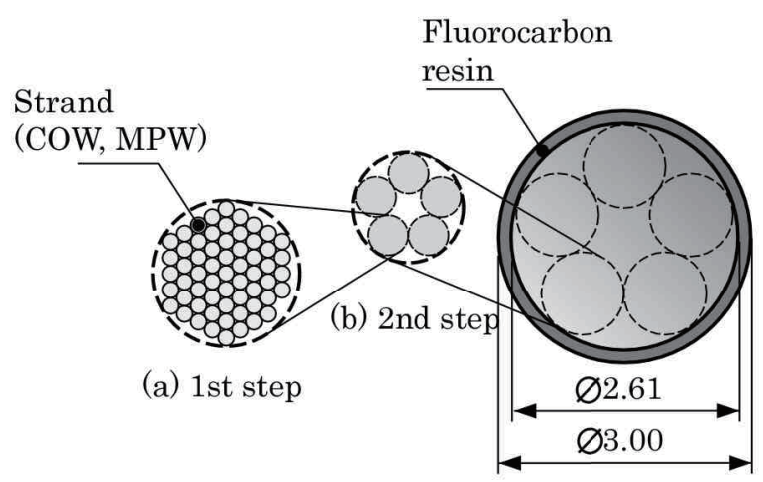

(c) Last step

Fig. 2 Structure of a litz wire (unit: $\mathrm{mm}$ ).

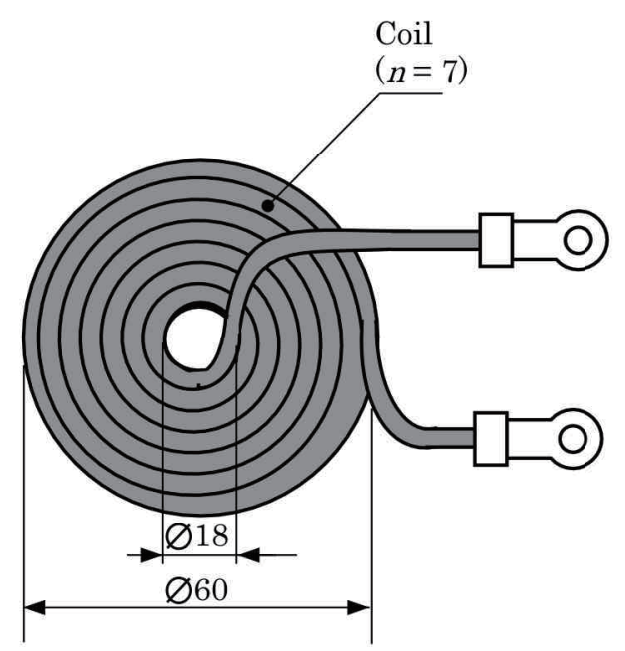

Fig. 3 Structure of an air core coil (unit: $\mathrm{mm}$ ).

た（撚りピッチ： $60 \mathrm{~mm}$ ). 次に Fig. $2(\mathrm{~b})$ のうに，孫撚 りを5本撚って子撚りを作成した（撚りピッチ： $5 \mathrm{~mm}$ ).さ らに Fig. 2 (c)のように, 子撚りを5本然って親然りとした あとに(撚りピッチ: $5 \mathrm{~mm}$ ) , 全体をフッ素樹脂でコーティ ングした.したがって，素線数 $N=1500$ 本である.光して， 実測には LCW , LMW ともに長さ $l=1.3 \mathrm{~m}$ のリッツ線を 用いた。

Fig. 3 に空心コイルの構造を示した . コイルは LCW と LMWの両者ともに $1.3 \mathrm{~m}$ のリッツ線を使用している.巻数 $n=7$ である. 外径は $60 \mathrm{~mm}$, 内径は $18 \mathrm{~mm}$ とした .

\section{3.リッツ線コイルの交流抵抗の理論式}

\section{1 表皮効果に起因する抵抗の理論式}

Fig. 4にMPWの表皮効果の理論式算出モデルを示した10). このモデルは, 無限の長さをもつ, 半径 $r_{1}$ の銅線に厚さ $r_{2}-$ $r_{1}$ の磁性薄膜がめつきされている構造である Fig. 1に示し たように $\mathrm{Fe}$ 薄膜と $\mathrm{Ni}$ 薄膜の厚さは, 弚れぞれ $0.6 \mu \mathrm{m}$ と

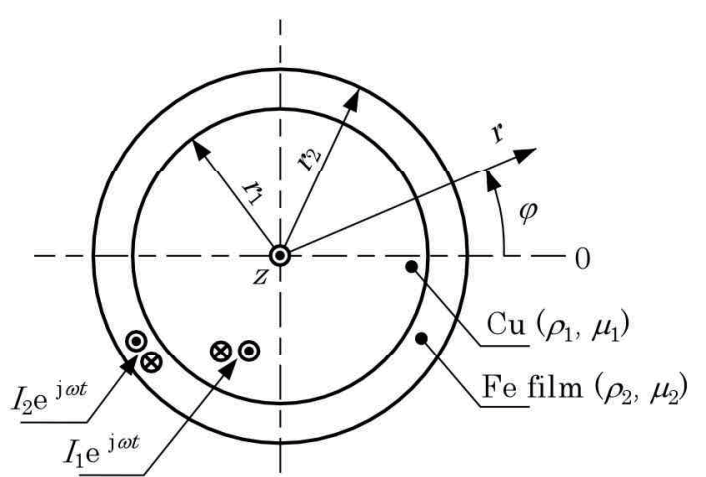

Fig. 4 Model for deriving expressions for the skin effect in MPWs.

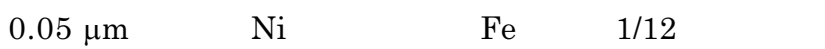
こで計算を簡便にするために Ni薄膜は $\mathrm{Fe}$ 薄膜として扱う ことにする ここでは, 周波数 $f$ の総電流 $I\left(=I_{1}+I_{2}\right)$ を流し たときに生ずる表皮効果に起因する抵抗を導出する．

Maxwellの方程式を用いて MPW 内部の磁界に関する微 分方程式を導出して, 直流抵抗を含めた MPWの表皮効果 に起因する抵抗 $R_{\mathrm{S}}^{\prime}$ を算出した ${ }^{10)}$. 次に，表皮効果に起因 する抵抗 $R_{\mathrm{S}}$ を明確にするために， $R_{\mathrm{S}}^{\prime}$ から直流抵抗 $R_{\mathrm{dc}}$ を 減算することで表皮効果に起因する抵抗 $R_{\mathrm{s}}$ は, 以下のよう になる10).

$$
\begin{aligned}
R_{s}= & \left(R_{s}{ }^{\prime}-R_{\mathrm{dc}}\right) \\
= & \operatorname{Re}\left[\frac{-\mathrm{j} \omega \mu_{2}\left\{C_{\mathrm{s} 2} \mathrm{~J}_{0}\left(\mathrm{j}^{3 / 2} k_{2} r_{2}\right)+B_{\mathrm{s} 2} \mathrm{~K}_{0}\left(\mathrm{j}^{1 / 2} k_{2} r_{2}\right)\right\}}{I}\right] \\
& -R_{\mathrm{dc}}(\Omega / \mathrm{m})
\end{aligned}
$$

$$
\begin{aligned}
& R_{\mathrm{dc}}=\frac{\rho_{1} \rho_{2}}{\pi\left\{\rho_{1}\left({r_{2}}^{2}-r_{1}^{2}\right)+\rho_{2} r_{1}^{2}\right\}}(\Omega / \mathrm{m}) \\
& k_{1}^{2}=\frac{\omega \mu_{1}}{\rho_{1}}\left(\mathrm{~m}^{-2}\right) \\
& k_{2}^{2}=\frac{\omega \mu_{2}}{\rho_{2}}\left(\mathrm{~m}^{-2}\right)
\end{aligned}
$$

$$
\begin{aligned}
C_{\mathrm{s} 2}= & \frac{I}{2 \pi k_{2} r_{2} \cdot \Delta_{\mathrm{s}}} \times\left\{k_{2} \mu_{1} \mathrm{~J}_{0}\left(\mathrm{j}^{3 / 2} k_{1} r_{1}\right) \mathrm{K}_{1}\left(\mathrm{j}^{1 / 2} k_{2} r_{1}\right)\right. \\
& \left.-\mathrm{j} k_{1} \mu_{2} \mathrm{~J}_{1}\left(\mathrm{j}^{3 / 2} k_{1} r_{1}\right) \mathrm{K}_{0}\left(\mathrm{j}^{1 / 2} k_{2} r_{1}\right)\right\}
\end{aligned}
$$

$$
\begin{aligned}
B_{\mathrm{s} 2}= & \frac{\mathrm{j} I}{2 \pi k_{2} r_{2} \cdot \Delta_{\mathrm{s}}} \times\left\{k_{1} \mu_{2} \mathrm{~J}_{0}\left(\mathrm{j}^{3 / 2} k_{2} r_{1}\right) \mathrm{J}_{1}\left(\mathrm{j}^{3 / 2} k_{1} r_{1}\right)\right. \\
& \left.-k_{2} \mu_{1} \mathrm{~J}_{0}\left(\mathrm{j}^{3 / 2} k_{1} r_{1}\right) \mathrm{J}_{1}\left(\mathrm{j}^{3 / 2} k_{2} r_{1}\right)\right\} \quad \text { (A) }
\end{aligned}
$$

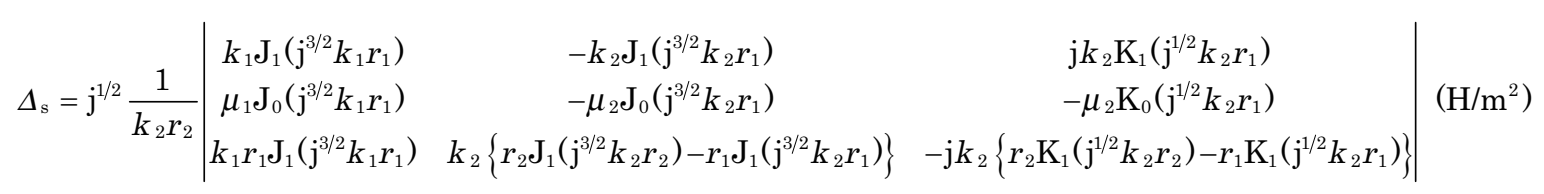


ここに， $R_{\mathrm{s}}{ }^{\prime}$ : 直流抵抗を含めた表皮効果に起因す る抵抗 $(\Omega / \mathrm{m}), \operatorname{Re}$ : 実数成分， $\omega$ : 角周波数 $(\mathrm{rad} / \mathrm{s})$, $\mu_{2}: \mathrm{Fe}$ 薄膜の透磁率 $(\mathrm{H} / \mathrm{m}), \mathrm{J}_{\mathrm{n}}$ : 第 1 種 $\mathrm{n}$ 次ベッセ 儿関数, $r_{2}: \mathrm{MPW} の$ 外半径 $(\mathrm{m}), \mathrm{K}_{\mathrm{n}}$ : 第 2 種 $\mathrm{n}$ 次变 形ベッセル関数, $\rho_{1}: \mathrm{Cu}$ の抵抗率 $(\Omega \mathrm{m}), \rho_{2}: \mathrm{Fe}$ の 抵抗率 $(\Omega \mathrm{m}), r_{1}:$ 銅線の半径 $(\mathrm{m}), \mu_{1}: \mathrm{Cu}$ の透磁率 $(\mathrm{H} / \mathrm{m})$

COWの直流抵抗と表皮効果に起因する抵抗は，下式の単 位長さあたりの直流抵抗と表皮効果に起因する抵抗の理論

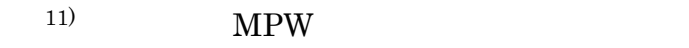

$$
\begin{aligned}
& R_{\mathrm{s}}=\operatorname{Re}\left[\mathrm{j}^{3 / 2} \frac{\omega \mu_{1} \mathrm{~J}_{0}\left(\mathrm{j}^{3 / 2} k_{1} r_{1}\right)}{2 \pi k_{1} r_{1} \mathrm{~J}_{1}\left(\mathrm{j}^{3 / 2} k_{1} r_{1}\right)}\right]-R_{\mathrm{dc}}(\Omega / \mathrm{m}) \\
& R_{\mathrm{dc}}=\frac{\rho_{1}}{\pi r_{1}{ }^{2}}(\Omega / \mathrm{m})
\end{aligned}
$$

\section{2 近接効果に起因する渦電流損の理論式}

近接効果に起因する抵抗 $R_{\mathrm{p}}$ は外部から作用する磁界に起 因する渦電流損に起因している.乥こで， $R_{\mathrm{p}}$ を計算するた めには,まず外部磁界 $H$ が作用した場合の滑電流損 $P_{\mathrm{e}}(H)$ を 求める必要がある.乥して, 渦電流損 $P_{\mathrm{e}}(H)$ を求めるために は導線に作用する磁界の強さ $H$ を算出する必要がある.

Fig. 5にMPWの近接効果の理論式算出モデルを示した $\left.{ }^{9}\right)$.

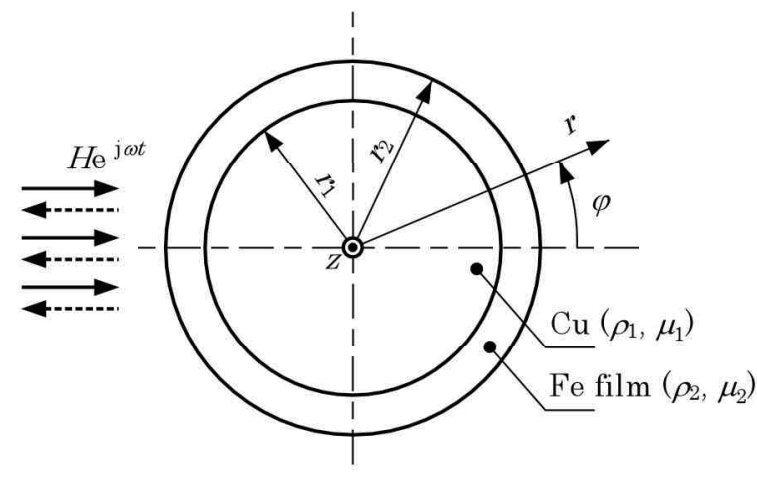

Fig. 5 Model for deriving expressions for the proximity effect in MPWs.

このモデルは, 無限の長さをもつ, 半径 $r_{1}$ の銅線に厚さ $r_{2}-$ $r_{1}$ の磁性薄膜がめっきされている構造であるここでは, 周 波数绞流磁界かMPWに垂直に作用するときの渦電流損 を求めて, LMWの近接効果に起因する抵抗を導出する。

単位長さあたりの MPW(素線)に外部磁界が作用した場 合の渦電流損を求める MPWの単位長さあたりの渦電流損 $P_{\mathrm{e}}$ は, 銅線内の単位長さあたりの渦電流損 $P_{\mathrm{e} 1}$ と $\mathrm{Fe}$ 薄膜内 の単位長さあたりの渦電流損 $P_{\mathrm{e} 2}$ の和で与えられる ${ }^{9)}$.乥れ ぞれの渦電流損は, 素線に作用する磁界の強さ $H$ の関数と なっており， $P_{\mathrm{e}}(H)$ は式(10)となる ${ }^{9)}$. なお , 式中のアスタ リスク $\left.{ }^{*}\right)$ は共役複素数を表している .

$$
\begin{aligned}
& P_{\mathrm{e}}(H)=P_{\mathrm{e} 1}(H)+P_{\mathrm{e} 2}(H) \\
& =-\frac{\pi \rho_{1} k_{1}{ }^{3} r_{1} C_{\mathrm{e} 1} C_{\mathrm{e} 1}{ }^{*}}{\mathrm{j}}\left\{\mathrm{j}^{3 / 2} \mathrm{~J}_{1}\left(\mathrm{j}^{-3 / 2} k_{1} r_{1}\right) \mathrm{J}_{2}\left(\mathrm{j}^{3 / 2} k_{1} r_{1}\right)-\mathrm{j}^{-3 / 2} \mathrm{~J}_{1}\left(\mathrm{j}^{3 / 2} k_{1} r_{1}\right) \mathrm{J}_{2}\left(\mathrm{j}^{-3 / 2} k_{1} r_{1}\right)\right\} \\
& +\frac{\pi \rho_{2} k_{2}{ }^{3}}{\mathrm{j}}\left[-C_{\mathrm{e} 2} C_{\mathrm{e} 2}{ }^{*} r_{2}\left\{\mathrm{j}^{3 / 2} \mathrm{~J}_{1}\left(\mathrm{j}^{-3 / 2} k_{2} r_{2}\right) \mathrm{J}_{2}\left(\mathrm{j}^{3 / 2} k_{2} r_{2}\right)-\mathrm{j}^{-3 / 2} \mathrm{~J}_{1}\left(\mathrm{j}^{3 / 2} k_{2} r_{2}\right) \mathrm{J}_{2}\left(\mathrm{j}^{-3 / 2} k_{2} r_{2}\right)\right\}\right. \\
& +C_{\mathrm{e} 2} C_{\mathrm{e} 2}{ }^{*} r_{1}\left\{\mathrm{j}^{3 / 2} \mathrm{~J}_{1}\left(\mathrm{j}^{-3 / 2} k_{2} r_{1}\right) \mathrm{J}_{2}\left(\mathrm{j}^{3 / 2} k_{2} r_{1}\right)-\mathrm{j}^{-3 / 2} \mathrm{~J}_{1}\left(\mathrm{j}^{3 / 2} k_{2} r_{1}\right) \mathrm{J}_{2}\left(\mathrm{j}^{-3 / 2} k_{2} r_{1}\right)\right\}-C_{\mathrm{e} 2} B_{\mathrm{e} 2}{ }^{*} r_{2}\left\{j^{3 / 2} \mathrm{~K}_{1}\left(\mathrm{j}^{-1 / 2} k_{2} r_{2}\right) \mathrm{J}_{2}\left(\mathrm{j}^{3 / 2} k_{2} r_{2}\right)\right. \\
& \left.-\mathrm{j}^{-1 / 2} \mathrm{~J}_{1}\left(\mathrm{j}^{3 / 2} k_{2} r_{2}\right) \mathrm{K}_{2}\left(\mathrm{j}^{-1 / 2} k_{2} r_{2}\right)\right\}+C_{\mathrm{e} 2} B_{\mathrm{e} 2}{ }^{*} r_{1}\left\{\mathrm{j}^{3 / 2} \mathrm{~K}_{1}\left(\mathrm{j}^{-1 / 2} k_{2} r_{1}\right) \mathrm{J}_{2}\left(\mathrm{j}^{3 / 2} k_{2} r_{1}\right)-\mathrm{j}^{-1 / 2} \mathrm{~J}_{1}\left(\mathrm{j}^{3 / 2} k_{2} r_{1}\right) \mathrm{K}_{2}\left(\mathrm{j}^{-1 / 2} k_{2} r_{1}\right)\right\} \\
& +C_{\mathrm{e} 2}{ }^{*} B_{\mathrm{e} 2} r_{2}\left\{\mathrm{j}^{-3 / 2} \mathrm{~K}_{1}\left(\mathrm{j}^{1 / 2} k_{2} r_{2}\right) \mathrm{J}_{2}\left(\mathrm{j}^{-3 / 2} k_{2} r_{2}\right)-\mathrm{j}^{1 / 2} \mathrm{~J}_{1}\left(\mathrm{j}^{-3 / 2} k_{2} r_{2}\right) \mathrm{K}_{2}\left(\mathrm{j}^{1 / 2} k_{2} r_{2}\right)\right\}-C_{\mathrm{e} 2}{ }^{*} B_{\mathrm{e} 2} r_{1}\left\{\mathrm{j}^{-3 / 2} \mathrm{~K}_{1}\left(\mathrm{j}^{1 / 2} k_{2} r_{1}\right) \mathrm{J}_{2}\left(\mathrm{j}^{-3 / 2} k_{2} r_{1}\right)\right. \\
& \left.-\mathrm{j}^{1 / 2} \mathrm{~J}_{1}\left(\mathrm{j}^{-3 / 2} k_{2} r_{1}\right) \mathrm{K}_{2}\left(\mathrm{j}^{\mathrm{i} / 2} k_{2} r_{1}\right)\right\}-B_{\mathrm{e} 2} B_{\mathrm{e} 2}{ }^{*} r_{2}\left\{\mathrm{j}^{1 / 2} \mathrm{~K}_{1}\left(\mathrm{j}^{-1 / 2} k_{2} r_{2}\right) \mathrm{K}_{2}\left(\mathrm{j}^{1 / 2} k_{2} r_{2}\right)-\mathrm{j}^{-1 / 2} \mathrm{~K}_{1}\left(\mathrm{j}^{1 / 2} k_{2} r_{2}\right) \mathrm{K}_{2}\left(\mathrm{j}^{-1 / 2} k_{2} r_{2}\right)\right\} \\
& +B_{\mathrm{e} 2} B_{\mathrm{e} 2}{ }^{*} r_{1}\left\{\mathrm{j}^{1 / 2} \mathrm{~K}_{1}\left(\mathrm{j}^{-1 / 2} k_{2} r_{1}\right) \mathrm{K}_{2}\left(\mathrm{j}^{1 / 2} k_{2} r_{1}\right)-\mathrm{j}^{-1 / 2} \mathrm{~K}_{1}\left(\mathrm{j}^{1 / 2} k_{2} r_{1}\right) \mathrm{K}_{2}\left(\mathrm{j}^{-1 / 2} k_{2} r_{1}\right)\right\} \quad(\mathrm{W} / \mathrm{m})
\end{aligned}
$$$$
C_{\mathrm{e} 1}=\frac{2 \mu_{0} \mu_{2} k_{2} H}{r_{2} \cdot \Delta_{\mathrm{e}}}\left[\mathrm{j}^{3 / 2}\left\{\mathrm{~J}_{0}\left(\mathrm{j}^{3 / 2} k_{2} r_{1}\right)-\mathrm{J}_{2}\left(\mathrm{j}^{3 / 2} k_{2} r_{1}\right)\right\} \mathrm{K}_{1}\left(\mathrm{j}^{1 / 2} k_{2} r_{1}\right)+\mathrm{j}^{1 / 2} \mathrm{~J}_{1}\left(\mathrm{j}^{3 / 2} k_{2} r_{1}\right)\left\{\mathrm{K}_{0}\left(\mathrm{j}^{1 / 2} k_{2} r_{1}\right)+\mathrm{K}_{2}\left(\mathrm{j}^{1 / 2} k_{2} r_{1}\right)\right\}\right]
$$$$
C_{\mathrm{e} 2}=\frac{2 \mu_{0} H}{r_{2} \cdot \Delta_{\mathrm{e}}}\left[\mathrm{j}^{3 / 2} \mu_{2} k_{1}\left\{\mathrm{~J}_{0}\left(\mathrm{j}^{3 / 2} k_{1} r_{1}\right)-\mathrm{J}_{2}\left(\mathrm{j}^{3 / 2} k_{1} r_{1}\right)\right\} \mathrm{K}_{1}\left(\mathrm{j}^{1 / 2} k_{2} r_{1}\right)+\mathrm{j}^{1 / 2} \mu_{1} k_{2} \mathrm{~J}_{1}\left(\mathrm{j}^{3 / 2} k_{1} r_{1}\right)\left\{\mathrm{K}_{0}\left(\mathrm{j}^{1 / 2} k_{2} r_{1}\right)+\mathrm{K}_{2}\left(\mathrm{j}^{1 / 2} k_{2} r_{1}\right)\right\}\right]
$$$$
B_{\mathrm{e} 2}=-\frac{2 \mathrm{j}^{3 / 2} \mu_{0} H}{r_{2} \cdot \Delta_{\mathrm{e}}}\left[\mu_{2} k_{1} \mathrm{~J}_{1}\left(\mathrm{j}^{3 / 2} k_{2} r_{1}\right)\left\{\mathrm{J}_{0}\left(\mathrm{j}^{3 / 2} k_{1} r_{1}\right)-\mathrm{J}_{2}\left(\mathrm{j}^{3 / 2} k_{1} r_{1}\right)\right\}-\mu_{1} k_{2} \mathrm{~J}_{1}\left(\mathrm{j}^{3 / 2} k_{1} r_{1}\right)\left\{\mathrm{J}_{0}\left(\mathrm{j}^{3 / 2} k_{2} r_{1}\right)-\mathrm{J}_{2}\left(\mathrm{j}^{3 / 2} k_{2} r_{1}\right)\right\}\right]
$$

$$
\Delta_{\mathrm{e}}=\left|\begin{array}{cccc}
-\mathrm{j}^{3 / 2} k_{1}\left\{\mathrm{~J}_{0}\left(\mathrm{j}^{3 / 2} k_{1} r_{1}\right)-\mathrm{J}_{2}\left(\mathrm{j}^{3 / 2} k_{1} r_{1}\right)\right\} & \mathrm{j}^{3 / 2} k_{2}\left\{\mathrm{~J}_{0}\left(\mathrm{j}^{3 / 2} k_{2} r_{1}\right)-\mathrm{J}_{2}\left(\mathrm{j}^{3 / 2} k_{2} r_{1}\right)\right\} & -\mathrm{j}^{1 / 2} k_{2}\left\{\mathrm{~K}_{0}\left(\mathrm{j}^{1 / 2} k_{2} r_{1}\right)+\mathrm{K}_{2}\left(\mathrm{j}^{1 / 2} k_{2} r_{1}\right)\right\} & 0 \\
\mu_{1} \mathrm{~J}_{1}\left(\mathrm{j}^{3 / 2} k_{1} r_{1}\right) & -\mu_{2} \mathrm{~J}_{1}\left(\mathrm{j}^{3 / 2} k_{2} r_{1}\right) & -\mu_{2} \mathrm{~K}_{1}\left(\mathrm{j}^{1 / 2} k_{2} r_{1}\right) & 0 \\
0 & \frac{1}{2} \mathrm{j}^{3 / 2} k_{2}\left\{\mathrm{~J}_{0}\left(\mathrm{j}^{3 / 2} k_{2} r_{2}\right)-\mathrm{J}_{2}\left(\mathrm{j}^{3 / 2} k_{2} r_{2}\right)\right\} & -\frac{1}{2} \mathrm{j}^{1 / 2} k_{2}\left\{\mathrm{~K}_{0}\left(\mathrm{j}^{1 / 2} k_{2} r_{2}\right)+\mathrm{K}_{2}\left(\mathrm{j}^{1 / 2} k_{2} r_{2}\right)\right\} & \frac{1}{r_{2}{ }^{2}} \\
0 & \mu_{2} \mathrm{~J}_{1}\left(\mathrm{j}^{3 / 2} k_{2} r_{2}\right) & \mu_{2} \mathrm{~K}_{1}\left(\mathrm{j}^{1 / 2} k_{2} r_{2}\right) & -\frac{\mu_{0}}{r_{2}}
\end{array}\right|
$$


ここに $, \mu_{0}:$ 真空の透磁率 $(\mathrm{H} / \mathrm{m}), H$ : 磁界の強さ

$(\mathrm{A} / \mathrm{m})$

COWの渦電流損は,下式の単位長さあたりの渦電流損の 理論式 ${ }^{12)}$ を用いて, MPW と同樣の手順で計算した .

$$
\begin{aligned}
P_{\mathrm{e}}= & -\frac{\pi \rho_{1} k_{1}{ }^{3} r_{1} C_{\mathrm{e}} C_{\mathrm{e}}{ }^{*}}{\mathrm{j}}\left\{\mathrm{j}^{3 / 2} \mathrm{~J}_{1}\left(\mathrm{j}^{-3 / 2} k_{1} r_{1}\right) \mathrm{J}_{2}\left(\mathrm{j}^{3 / 2} k_{1} r_{1}\right)\right. \\
& \left.-\mathrm{j}^{-3 / 2} \mathrm{~J}_{1}\left(\mathrm{j}^{3 / 2} k_{1} r_{1}\right) \mathrm{J}_{2}\left(\mathrm{j}^{-3 / 2} k_{1} r_{1}\right)\right\} \quad(\mathrm{W} / \mathrm{m}) \\
C_{\mathrm{e}}= & \frac{4 \mu_{0} H r_{1}}{\mathrm{j}^{3 / 2} \mu_{0} k_{1} r_{1}\left\{\mathrm{~J}_{0}\left(\mathrm{j}^{3 / 2} k_{1} r_{1}\right)-\mathrm{J}_{2}\left(\mathrm{j}^{3 / 2} k_{1} r_{1}\right)\right\}+2 \mu_{1} \mathrm{~J}_{1}\left(\mathrm{j}^{3 / 2}\right.}
\end{aligned}
$$

(A)

Fig. 6にリッツ線を用いた空心コイルの任意の素線1本が 任意の別の素線に作る磁界の強さを示した .リッツ線の素 線番号 $b\left(r_{\mathrm{b}}, z_{\mathrm{b}}\right)$ の素線に電流Iが流れており，リッツ線の素 線番号 $a\left(r_{\mathrm{a}}, z_{\mathrm{a}}\right)$ の素線に磁界の強さ $H_{\mathrm{ab}}$ が作用する. 兴の 磁界の強さ $H_{\mathrm{ab}}$ の $r$ 方向成分 $H_{\mathrm{rab}}$ と $z$ 方向成分 $H_{\mathrm{zab}}$ は光れ光 れ式(17)と(18)となる ${ }^{13)}$.

$$
\begin{aligned}
H_{r a b}= & \frac{I}{2 \pi} \frac{Z_{a}-Z_{b}}{r_{b} \sqrt{\left(r_{a}+r_{b}\right)^{2}+\left(Z_{a}-Z_{b}\right)^{2}}} \\
& \left\{-K\left(k_{\mathrm{c}}\right)+\frac{r_{a}{ }^{2}+r_{b}{ }^{2}+\left(z_{a}-Z_{b}\right)^{2}}{\left(r_{a}-r_{b}\right)^{2}+\left(Z_{a}-Z_{b}\right)^{2}} \cdot E\left(k_{\mathrm{c}}\right)\right\}
\end{aligned}
$$

(A/m) (17)

$$
\begin{aligned}
H_{z a b}= & \frac{I}{2 \pi} \frac{1}{\sqrt{\left(r_{a}+r_{b}\right)^{2}+\left(z_{a}-z_{b}\right)^{2}}} \\
& \left\{K\left(k_{\mathrm{c}}\right)-\frac{r_{b}{ }^{2}-r_{a}{ }^{2}+\left(z_{a}-z_{b}\right)^{2}}{\left(r_{a}-r_{b}\right)^{2}+\left(z_{a}-z_{b}\right)^{2}} \cdot E\left(k_{\mathrm{c}}\right)\right\}
\end{aligned}
$$

(A/m) (18)

$$
k_{\mathrm{c}}=\sqrt{\frac{4 r_{a} r_{b}}{\left(r_{a}+r_{b}\right)^{2}+\left(z_{a}-z_{b}\right)^{2}}}
$$

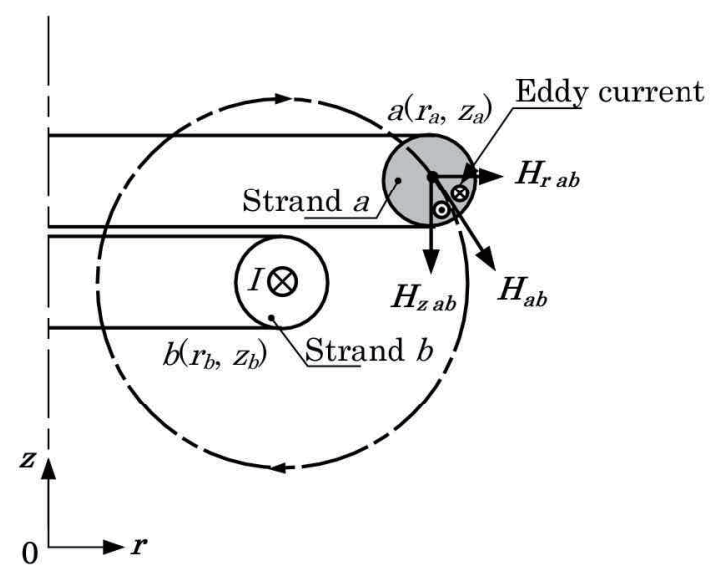

Fig. 6 Magnetic field made arbitrary by a strand of litz wire.
ここに,I: 素線に流れる電流 $(\mathrm{A}), r_{\mathrm{b}}, Z_{\mathrm{b}}$ : 電流 $I$ が 流れているリッツ線の素線番号 $b$ 座標 $(\mathrm{m}), r_{\mathrm{a}}, Z_{\mathrm{a}}$ : 磁界が作用する任意の素線番号 $\mathrm{a}$ の座標 $(\mathrm{m}), K$ : 第 1 種完全楕円積分関数, $E$ : 第 2 種完全楕円積分関数

素線aに磁界の強さHが作用することで素線aの内部に渦 電流が生ずる .さらに , 素線数 $N$ 本のリッツ線では , 任意 の素線 $a\left(r_{a}, z_{a}\right)$ に作用する磁界の強さ $H$ は , 他の $(N-1)$ 本の素線による磁界の強さのベクトル和となる .

次に,単位長さあたりのMPW (素線) の渦電流損を用い て素線数 $N$ 本，巻数 $n$ 回の空心コイルに生ずる近接効果に 起因する抵抗を導出する.まず,リッツ線を用いた空心コイ ルに用いる素線の物理特性 (比透磁率, 抵抗率, 長さ,およ び周波数) と座標を決定する.光して,素線 bから任意の素 線 $a$ に作用する磁界の強さを導出する .ここで, 式(17)お よび式(18)を用いて任意の点 $a$ に作用する $r$ 方向成分と $z$ 方 向線分の磁界の強さ $H_{r}$ aおよび $H_{z}$ aを求めると产れ光れ次 式となる．

$$
\begin{aligned}
& H_{r_{a}}=\sum_{b=1, a \neq b}^{N} H_{r^{a} a} \quad(\mathrm{~A} / \mathrm{m}) \\
& H_{z a}=\sum_{b=1, a \neq b}^{N} H_{z a b} \quad(\mathrm{~A} / \mathrm{m})
\end{aligned}
$$

式(20)および式(21)の合成和を求めることでリッツ線を 用いた空心コイルの任意の点aに作られる磁界の強さ $H_{a}$ は 下式となる

$$
H_{a}=\sqrt{H_{r a}{ }^{2}+H_{z a}{ }^{2}} \quad(\mathrm{~A} / \mathrm{m})
$$

次に，磁界が作用する素線 1 本について，「素線1本に生 ずる渦電流損 $\left.P_{\mathrm{e}}\right\lrcorner$ と「素線 1 本の長さ $\left.2 \pi r_{\mathrm{n} N}\right\lrcorner$ との積を素線 数 $N$ 本足し合わせ, 巻数 $n$ 回まで求める .ここで, リッツ 線を用いた空心コイルの撚り率を補正するために，周ごと に素線に生ずる渦電流損を算出して平均している これは， リッツ線を用いた空心コイルの交流抵抗を求める際に，以 下の考え方を適用するためである .

a)「リッツ線の任意の 1 区間で生ずる渦電流損の和」と 「リッツ線の任意の素線 1 本で生ずる撚りピッチ 1 周期分の 渦電流損」は等しい.

このとき,磁界の強さHの関数である $P_{\mathrm{e}}$ は 式(10)(LMW) および式(15)(LCW)より求められた值を代入する.

以上から，リッツ線を用いた空心コイルの素線1本に生ず る近接効果に起因する損失 $P_{\mathrm{p}}$ は下式となる .

$$
P_{\mathrm{p}}=\sum_{n=1}^{n} \frac{\sum_{N=1}^{N} P_{\mathrm{e}}\left(H_{a}\right) \cdot 2 \pi r_{n N}}{N} \quad(\mathrm{~W})
$$

ここに, $r_{\mathrm{n} N}$ : 中心からコイルの巻数 $n$ 周目の素線 番号 $N$ $N$ リツ線コイルの半径 $(\mathrm{m})$ 


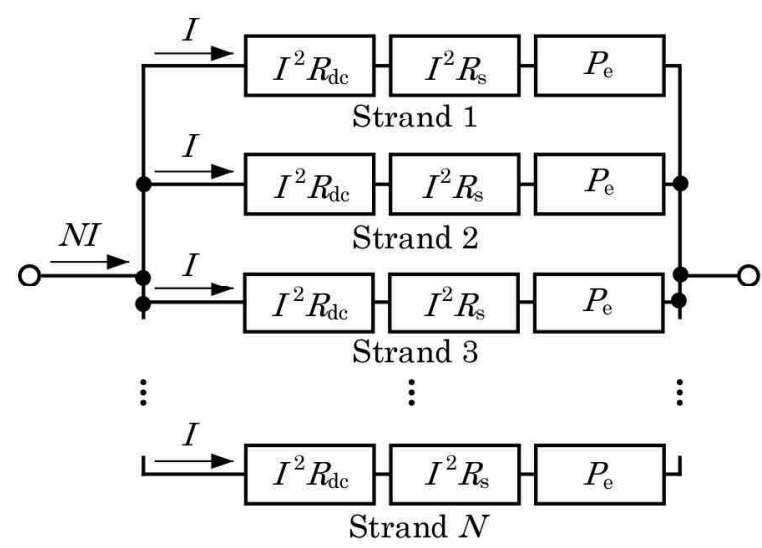

(a) Loss in each strand

Fig. 7 Loss in a coil using litz wire.

\section{3 空心コイルの交流抵抗}

Fig. 7にリッツ線に生ずる各損失を示した .リッツ線を用 いた空心コイルの各素線の抵抗は, 各素線が十分撚られて いるとの仮定に基づいて以下に示した損失成分が等しい．

1) 直流抵抗に起因する損失

2) 表皮効果に起因する損失

3) 近接効果に起因する損失

このためにリッツ線を用いた空心コイルの損失は，Fig. 7(a)に示したように各素線において損失が等しい並列回路 で表わされる．光して，空心コイルで生ずる全ての損失電力 Pは Fig. 7(b)のようにまとめて式(24)となる . ただし , 式 $(24) の R_{\mathrm{s}}, R_{\mathrm{dc}}$ は光れ攵れ式(1)と(8)，式(2)と(9)で表さ れる.

$$
\begin{aligned}
& P=\left\{\left(R_{\mathrm{s}}+R_{\mathrm{dc}}\right) \cdot I^{2} l+P_{\mathrm{e}}\right\} N \quad(\mathrm{~W}) \\
& \text { ここに }, I: \text { リッツ線の長さ }(\mathrm{m})
\end{aligned}
$$

式(24)に示した空心コイルで生ずる全ての損失電力を電 流の2乗 $(N I)^{2}(\mathrm{~A})$ で割ることでリッツ線を用いた空心コイ ルの抵抗となる .

$$
\begin{aligned}
R & =\frac{\left\{\left(R_{\mathrm{dc}}+R_{\mathrm{s}}\right) \cdot I^{2} I+P_{\mathrm{e}}\right\} N}{(N I)^{2}} \\
& =\frac{\left\{\left(R_{\mathrm{dc}}+R_{\mathrm{s}}\right) \cdot 1+\frac{P_{\mathrm{e}}}{I^{2}}\right\}}{N}(\Omega)
\end{aligned}
$$

空心コイルの交流抵抗 $R$ 導出過程をまとめると以下と なる。

1)導線の物理的特性(比透磁率, 抵抗率, および周波数)の 入力

2)各素線の中心座標の入力

3)直流抵抗 $R_{\mathrm{dc}}$ の計算

4)表皮効果に起因する抵抗 $R_{\mathrm{S}}$ の計算

5)各素線に作用する磁界 $H$ の計算

6)各素線の近接効果に起因する損失 $P_{\mathrm{e}}$ の計算

7)空心コイルに生ずる全損失 $P$ の計算

8)交流抵抗 $R$ の計算

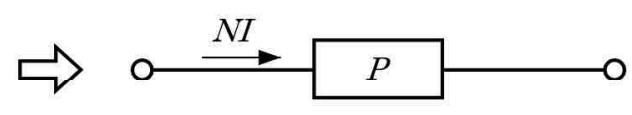

(b) Total loss in a coil using litz wire

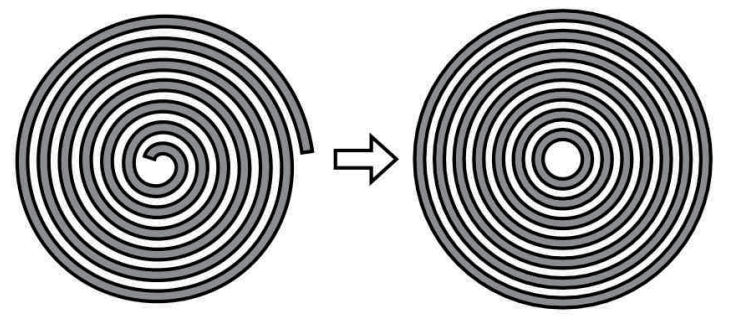

(a) Spiral shape

(b) Concentric circle shape

Fig. 8 Shape approximation of a coil using litz wire.

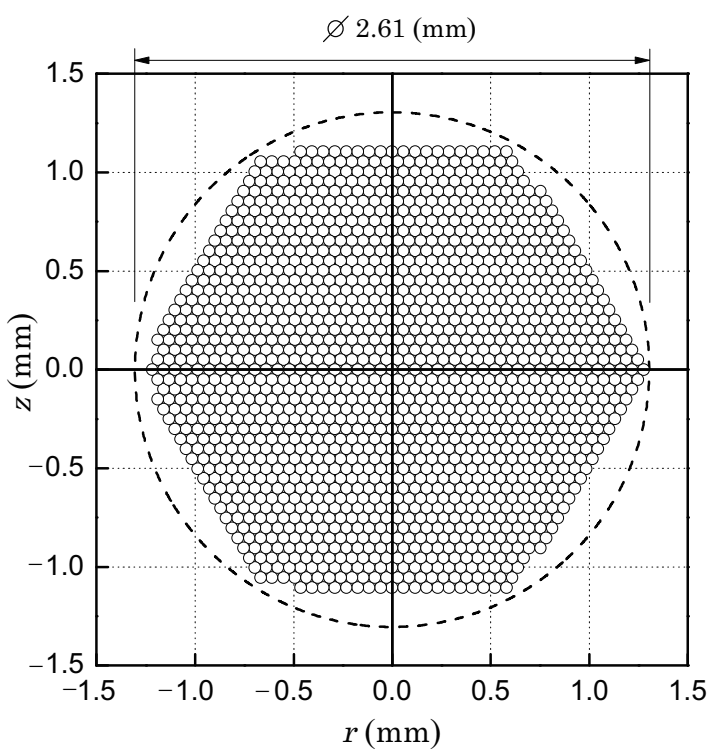

Fig. 9 Coordinates for theoretical calculation of the resistance of a litz wire.

\section{4. 空心コイルの交流抵抗}

Fig. 8にリッツ線コイルの形状近似を示した.リッツ線コ イルの実際の形状は ,Fig. 8 (a)に示した螺旋状をしている が,簡便に考えるために理論計算ではFig. 8 (b)に示した同 心円状に近似する、螺旋状をしたリッツ線コイルを同心円 状に近似する際には，以下の事項を仮定した .

1）1 周ごとの直流抵抗が等しい，すなわち，1 周ごとの リッツ線の長さが等しい . 


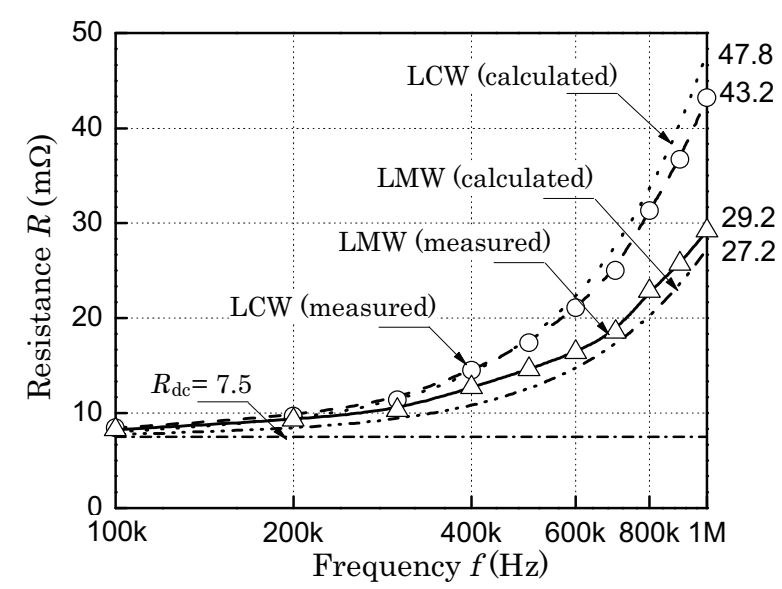

Fig. 10 Comparison of the measured and calculated values of the resistance of an air core coil $(l=1.3 \mathrm{~m}$, $\mathrm{Cu}: \rho_{1}=1.72 \times 10^{-8} \Omega \mathrm{m}, \mu_{\mathrm{r} 1}=0.999991, \mathrm{Fe}: \rho_{2}=9.8$ $\left.\times 10^{-8} \Omega \mathrm{m}, \mu_{\mathrm{r} 2}=120\right)$.

Fig. 9 にリッツ線の理論計算に用いた座標を示した ${ }^{14)}$. 1500本ある素線を,簡便に解析できるように中心から 23 層 は整列に並べ,余った素線は最外層に均等に配置した．

Fig. 10にリッツ線の抵抗の計算值と実測値との比較を示 した .ここで，解析に用いた $\mathrm{Fe}$ 薄膜の比透磁率 $\mu_{\mathrm{r} 2}=120$ は試料振動型磁力計を用いて求めた実測值である.Rの実 測には，インピーダンスアナライザ(Agilent, 4294A)を用 いて測定した.素線数 $N=1500$ 本, 長さ $l=1.3 \mathrm{~m}$ の LCW コイルと LMW コイルの共振周波数は，ともに $40 \mathrm{MHz}$ で あり,周波数 $1 \mathrm{MHz}$ 以下の範囲においては共振の影響は無 い. 周波数 $f=100 \mathrm{kHz}$ から $1 \mathrm{MHz}$ の範囲において LCW

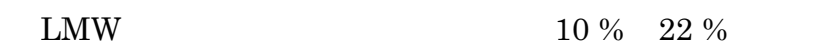
た.LMWの磁束の流れは,鉄薄膜に磁束か誘導されるため に複杂隹となる . 本論文では, LMWの磁束の流れをLCW と 等価として考えている .これがLMWの計算誤差が大きく なった原因である . 周波数 $1 \mathrm{MHz}$ における LCW と LMW の抵抗は，光れ光れ $43.2 \mathrm{~m} \Omega$ と $29.2 \mathrm{~m} \Omega$ であり，34\%低 減した。

\section{5. あとがき}

本論文で述べたことをまとめると以下のようになる .

(1) 空心コイルの交流抵抗の理論式

LMWの素線1本ごとを考慮した直流抵抗と表皮効果に起 因する抵抗および近接効果に起因する抵抗の理論式を光れ
ぞれ導出した . 周波数 $f=100 \mathrm{kHz}$ から $1 \mathrm{MHz}$ の範囲にお いて LCW と LMW の抵抗の計算誤差は, 弚れ光れ $10 \%$ と $22 \%$ であった .

\section{(2) LMWの有用性}

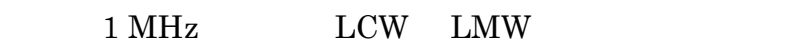
$43.2 \mathrm{~m} \Omega$ と $29.2 \mathrm{~m} \Omega$ であり,リッツ線の素線にMPW いることにより交流抵抗が $32 \%$ 低減した .

\section{References}

1) H. Yonemori, and M. Kobayashi : IEEE Trans. on IA., 127, 3, pp. 234-240, (2007).

2) K. Shiba, M. Nukaya, T. Tsuji, and K. Koshiji: J. Jpn. Soc. Med. Bio. Eng., 43, 4, pp. 670-676, (2005).

3) T.Imura, and Y. Hori: IEE Japan, 129, 7, pp. 414-417, (2009).

4) K.Koshiji, T. Utsunomiya, S. Takaya, H. Takano, T. Nakaya, M. Kinoshita, H. Noda, S. Fukuda, and T. Akutsu: J. Jpn. Soc. Med. Bio. Eng., 16, 1, pp. 167-170, (1987).

5) K.Koshiji, K. Masuda, E. Shu, T. Utsunomiya, S. Takaya, H. Takano, and T. Akutsu: J. Jpn. Soc. Med. Bio. Eng., 18, 2, pp. 533-536, (1989).

6) T. Mizuno, T. Suzuki, T. Asahina, S. Enoki, H. Shinagawa, S. Uehara, and H. Kitazawa: Technical Meeting on Magnetics, IEEJ, MAG-06-83, pp. 7-15, (2006).

7) T. Mizuno, T. Suzuki, T. Asahina, M. Noda, S. Enoki, H. Shinagawa, S. Uehara, and H. Kitazawa: Technical Meeting on Magnetics, IEEJ, MAG-06-177, pp. 51-56, (2006).

8) T. Mizuno, S. Enoki, T. Hayashi, T. Asahina, and H. Shinagawa: IEEE Trans. on Magn., 43, 2, pp. 543-548, (2007).

9) S. Yoshimura, S. Yoshihara, T. Shirakashi, E. Sato and K. Ishii: Characteristics of high- $Q$ coils composed of Fe-plated $\mathrm{Cu}$ wire, Magneto-Electronics International Symposium, pp.485-487, (1994).

10) T. Mizuno, T. Suzuki, T. Asahina, M. Noda, S. Enoki, H. Shinagawa, S. Uehara, and H. Kitazawa: IEEJ Trans. FM., 127, 10, pp. 611-620 (2007).

11) G. H. Brown, and C. N. Holyer: Theory and application of ratio-frequency, pp.4-21 ( D. Van nostrand company, 1947).

12) J. Lammeraner, and M. Stafl: Eddy current, pp.91-98 (Iliffe Book Ltd., 1964).

13) Robert A. Schill, Jr.: IEEE Trans. on Magn., 39, 2, p.965, (2003).

14) T. Mizuno, K. Matsushita, K. Iida, A. Kamiya, and D. Yamamoto: General relation for the vector magnetics field of a circular current loop, a closer look, Japan Society of AEM, 17, 2, pp.342-347, (2009).

2009 年1 0 月 7 日受理, 2010 年1月 8 日再受理, 2010 年3 月 17 日採録 